\title{
Comparison of Phenylephrine, Ephedrine, and Mephentermine for Control of Hypotension After Spinal Anesthesia in Subumbilical Surgery
}

\author{
Shwresh Saeer
}

\begin{abstract}
Background: Neuraxial anaesthesia remains the preferred choice for infra-umbilical surgeries Three vasopressors phenylephrine, ephedrine and mephentermine in intravenous bolus form, are effective in maintenance of blood pressure (BP). Absolute supremacy of one vasopressor over the others is not yet established. The current study was undertaken to compare the three vasopressor for maintenance of BP during spinal anesthesia. Material and Methods: Clinical observational study over a period of one year was conducted in a tertiary medical center and teaching hospital in Maharashtra. Ninety patients of American Society of Anaesthesiologist classification: class I and II were distributed into three groups of thirty patients each. Following hypotension, group A received ephedrine $10 \mathrm{mg}$, group B received mephentermine $10 \mathrm{mg}$ and group $C$ received phenylephrine $100 \mu \mathrm{g}$ as intravenous bolus in $1 \mathrm{ml}$ of $0.9 \%$ sodium chloride solution. Blood pressure, heart rate and oxygen saturation were recorded every 2 minutes for first 10 minutes and then every 15 minutes for one hour. Results: In ephedrine group $9(30 \%)$ patients required second dose and 8 (26\%) patients developed tachycardia. In mephentermine group, 33\% patients developed tachycardia and 4 (13\%) developed hypertension. In phenylephrine group 8 (26\%) developed bradycardia and $3(10 \%)$ developed severe bradycardia pulse rate dropped to 42 /min corrected by giving injection atropine and in all patients BP was maintained within 6-8 minutes after giving vasopressors and only in ephedrine group i.e. 9 patients required two doses of ephedridine. Conclusions: All the three vasopressors were equally effective in maintaining blood pressure after spinal anaesthesia induced hypotension. Elevation of systolic pressure in phenylephrine group was significantly high for first 6 min of bolus dose as compared to other two and bradycardia in these patients was a significant finding.
\end{abstract}

Keywords: hypotension, surgery, tachycardia, bradycardia

\section{Introduction}

Regional anaesthesia is the preferred choice for infraumbilical surgeries like vaginal or abdominal hysterctomies and surgeries like fractures of lower-limbs across the world. ${ }^{1}$ It has established itself as one of the most popular techniques for lower limb and lower abdominal procedures as it as has many advantages like adequate relaxation of the muscles and is easy to administer. It offers a fast, profound and high quality sensory and motor block in patients undergoing infra umbilical surgeries. ${ }^{1}$ Hypotension usually occurs after spinal anaesthesia and should be treated with prompt action and aggressive management to stabilise the patient so that the risk of cardiac arrest is minimised. The simplicity of the technique, reliable effect and lack of all those complications that are associated with general anaesthesia has made it a safe alternative. ${ }^{2}$ The fatality rate directly attributed to anaesthesia. is approximately 17 fold more frequent with GA as compared to regional anaesthesia. ${ }^{3}$ Careful positioning volume preloading with crystalloids or colloids has been used to prevent it, but these are not complete measures ${ }^{4}$ and vasopressors are required to correct hypotension quickly, these agents have been tried to counteract the hypotensive effect of subarachnoid block, and there main action being vasoconstriction and increase in the cardiac output. ${ }^{5}$ In practice, the most commonly used drugs are the sympathomimetic agents which exert their effects through the adrenergic receptors, either acting directly or indirectly. Also it has been found that the three vasopressors phenylephrine, ephedrine and mephentermine in intravenous bolus form, are effective in maintenance of arterial pressure within $20 \%$ limit of baseline, although action of phenylephrine is faster as compared to ephedrine and mephentermine $e^{5}$. Thus it is clear that which drug among the three is superior to the other is not yet concluded and hence we decided to conduct the present study.

\section{Objective}

The objective of this study was to compare the control of blood pressure and assess safety profile of three vasopressors phenylephrine, ephedrine and mephentermine during spinal anaesthesia in lower abdominal surgeries.

\section{Material and Methods}

A clinical observational study over a period of one year from June 2018 to June 2019 was conducted in the Department of Anaesthesiology at a tertiary care medical center and teaching hospital. All patients undergoing infaumbilical surgeries with American Association of Anaesthesiology Classification (ASA) grade 1 and 2 were included those with ASA grade 3 and 4, pregnant women, and patients not giving consent were excluded. Enrolled patients were divided into Group A where ephidrine was given and Group B where mephentramine was used and Group C where phenylephine was used Following hypotension, defined as blood pressure less than $90 \mathrm{~mm}$ of $\mathrm{Hg}$ systolic and less than $60 \mathrm{~mm} \mathrm{Hg}$ diastolic. Group A received ephedrine $10 \mathrm{mg}$, group $B$ received mephentermine $10 \mathrm{mg}$ and group $\mathrm{C}$ received phenylephrine $100 \mu \mathrm{g}$ as intravenous bolus in $1 \mathrm{ml}$ of $0.9 \%$ sodium chloride solution. Vital parameters like blood pressure (systolic, diastolic and mean), heart rate and oxygen saturation were recorded preoperatively as well as intra-operatively every 2 minutes for the first 10 minutes and then every 15 minutes for one hour First assessment of the patient was done during the pre 
anaesthesia workup to rule out any conditions listed in the exclusion criteria A second assessment was done immediately prior to the SA after confirming that there are no contraindication BP was checked immediately after SA and also every 2 minutes for first 10 minutes If hypotension was detected ie when systolic BP was less than $90 \mathrm{~mm}$ of $\mathrm{Hg}$ then vasopressors were given. Any side effects observed were recorded. Patients were counselled during the routine pre-anaesthesia check-up and also prior to anaesthesia.

\section{Anaesthesia procedure}

Patients were kept nil by mouth for 6-8 hours prior to surgery. On the day of surgery, patients received premedications with a single injection of metoclopramide 10 $\mathrm{mg}$ and a single injection of pantoprazole $40 \mathrm{mg}$ intravenous one hour prior to surgery. After securing intravenous access and attaching monitors patients in all three groups were preloaded with Ringer Lactate $10 \mathrm{ml} / \mathrm{kg} 20 \mathrm{~min}$ before spinal anaesthesia. The operating table was kept flat. Using aseptic precautions, lumbar puncture performed at L3-4 using midline approach with 26 Gauge sterile Quinke's needle with the patient in sitting position. After visualization of clear and free flow of cerebrospinal fluid bupivacaine $0.5 \%$ heavy, $2.2 \mathrm{ml}$ bolus was injected into L3-4 subarachnoid space patients then turned to supine position with a wedge under the right buttock. Thereafter oxygen through facemask at the rate of $4 \mathrm{~L} / \mathrm{min}$ was administered.

Antiemetic injection ondansetron $0.08-0.1 \mathrm{mg} / \mathrm{kg}$ and anxiolytic injection midazolam $0.02-0.05 \mathrm{mg} / \mathrm{kg}$ was given. Intra-operative fluids were given as necessary depending on the blood loss and hemodynamic parameters. After recording basal heart rate (HR), systolic blood pressure (SBP), diastolic blood pressure (DBP), mean arterial pressure (MAP), and $\mathrm{SPO}_{2}$ patients were monitored according to the protocol as indicated in the study design section. If hypotension occurred, one of the vasopessor was given by the anaesthesiologist. Time of vasopressor administration, duration of surgery, and time of hypotension was recorded as minutes after start of surgery. All incidences of bradycardia (heart rate less than $60 \mathrm{bpm}$ ) were treated with intravenous atropine $0.6 \mathrm{mg}$; any tachycardia (HR $>30 \%$ above the basal HR) was noted. Intra-operative nausea and vomiting were recorded. Patients were monitored postoperatively in the recovery room for 2 hours

\section{Statistical analysis}

Descriptive analysis is presented in the result section.

Categorical data are presented as number and percentages.

Group wise comparison of efficacy and side effects is presented.

\section{Results}

A total of 90 patients were enrolled in the study. Out of these, $40(44 \%)$ were male patients posted for lower limb surgeries and $50(55 \%)$ were females posted for vaginal/ abdominal hysterectomies. A total of 22 (24.4\%), 34 $(37.8 \%)$ and $34(37.8 \%)$ patients received ephedrine, mephentermine and phenylephrine respectively. Ephedrine, mephentermine and phenylephrine groups comprised of 10 $(45.45 \%), 16(47.06 \%)$ and $14(41.18 \%)$ male patients respectively. The corresponding number of female patients were $12(54.55 \%), 18(52.94 \%)$ and $20 \quad(58.82 \%)$ respectively (Figure 1)

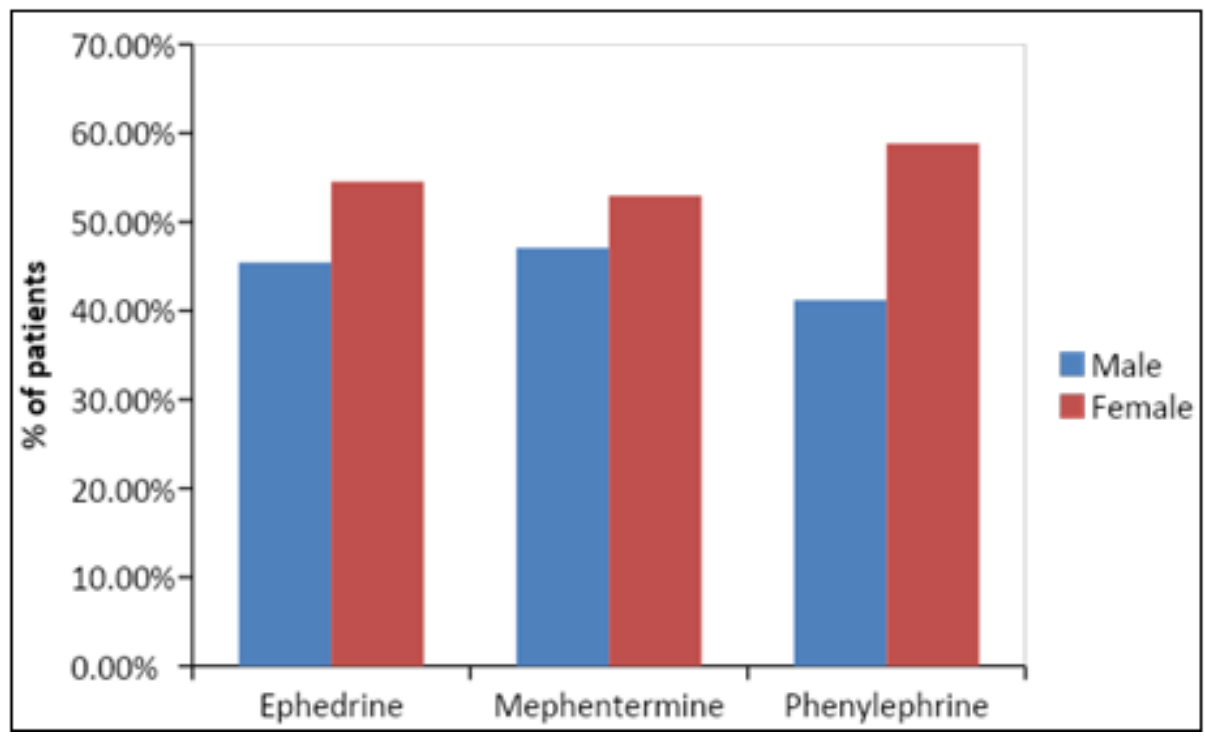

Figure 1: Gender distribution of patients in the study

In a total of $9(30 \%)$ patients from ephedrine group hypotension persisted. The mean arterial pressure after 2 minutes of intravenous bolus was $65 \mathrm{~mm} \mathrm{Hg}$, hence these patients required second dose (Figure 2). In all patients BP was controlled after an initial hypotension which developed within 6 to 8 minutes after patient was made to lie down after spinal anaesthesia. 


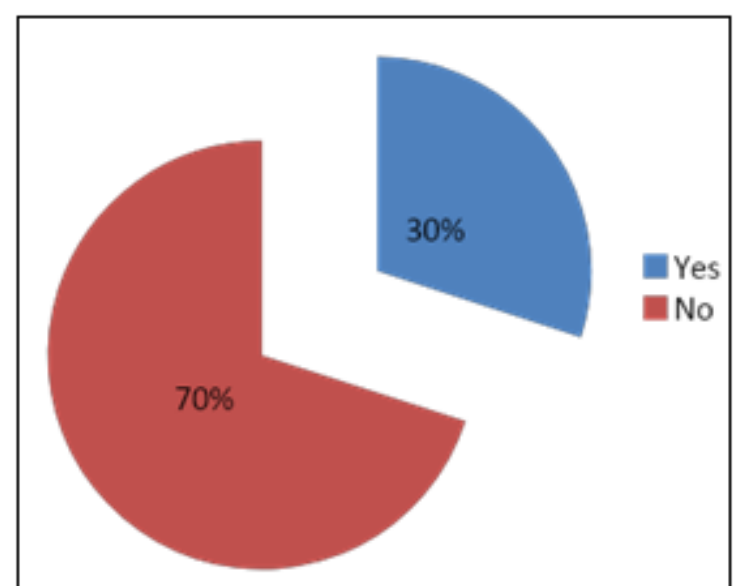

Figure 2: Percentage of patients requiring second dose of ephedrine

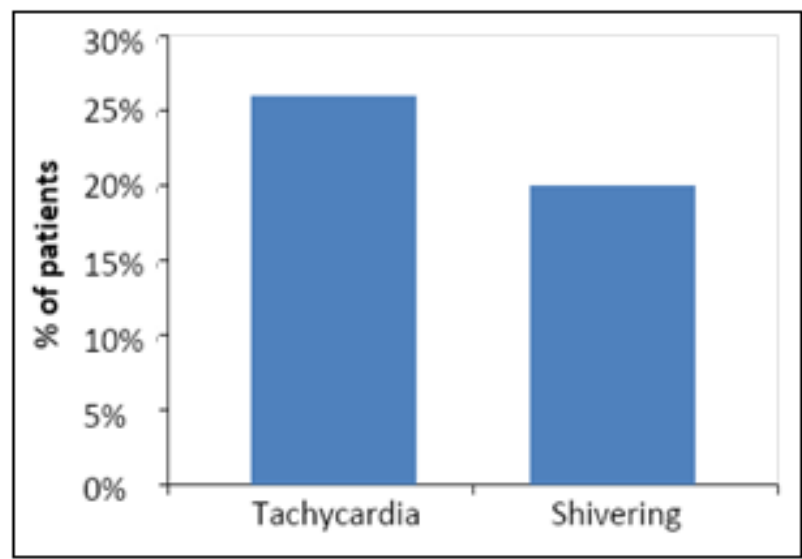

Figure 3: Side effects in patients receiving ephedrine

A total of $8(26 \%)$ patients had tachycardia and $20 \%$ of patients had shivering (Figure 3).

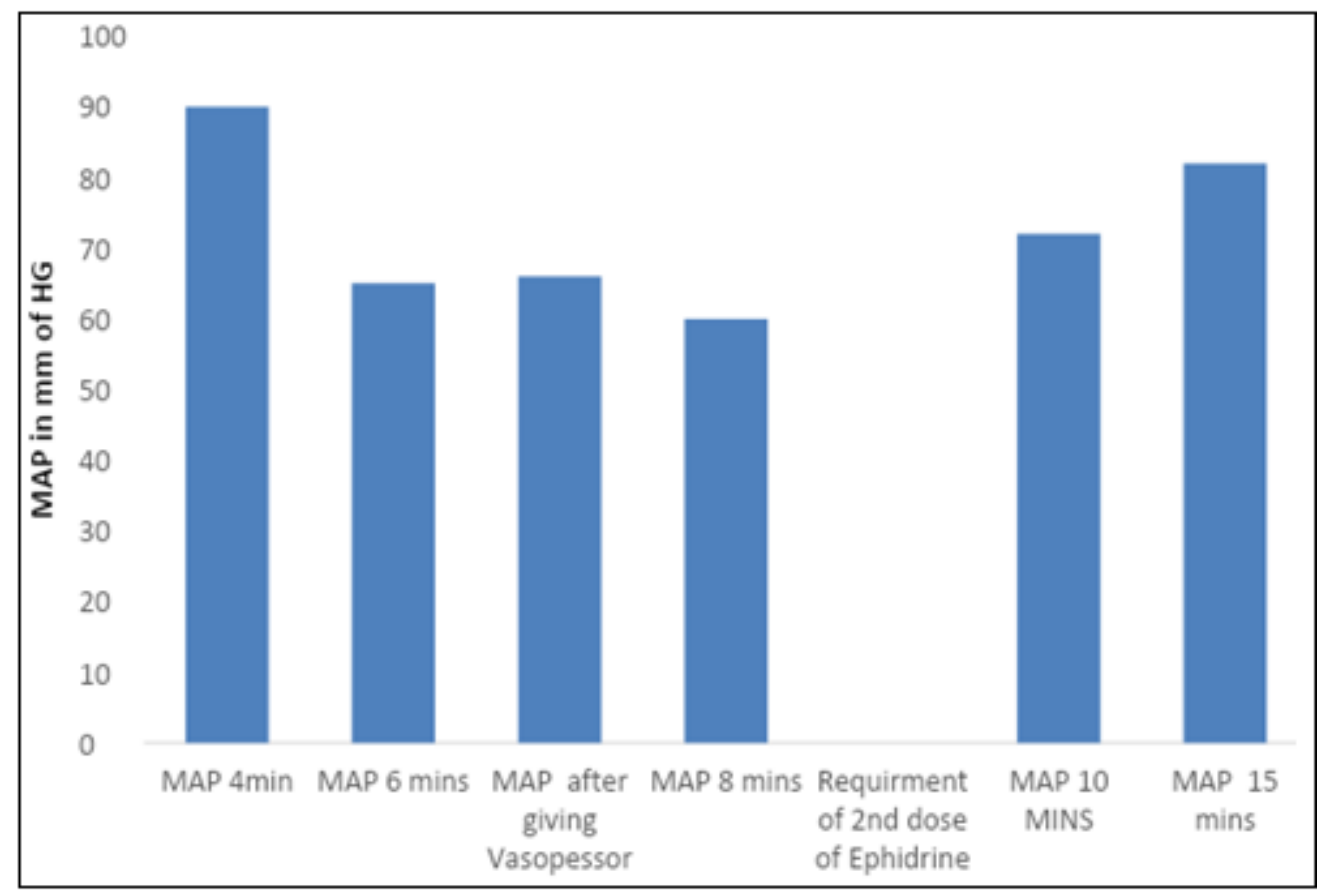

Figure 4: Mean arterial pressure in Group A

A total of $10(33 \%)$ patients in mephentramine developed tachycardia and 4 (13\%) developed hypertension because of its ionotropic action (Figure 5). In patients receiving mephentermine, MAP increased to $90 \mathrm{~mm} \mathrm{Hg}$ after an initial drop to $65 \mathrm{~mm} \mathrm{Hg}$ within 3 minutes after vasopressor bolus and BP was well under control in all patients

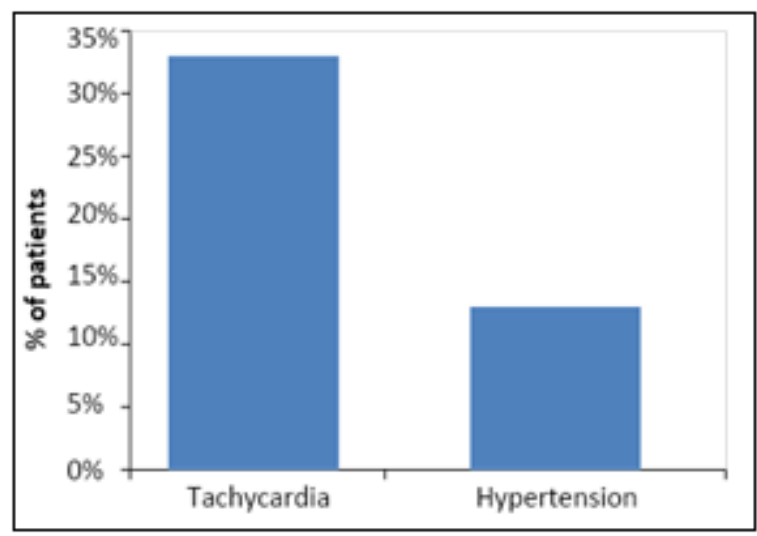

Figure 5: Side effects in patients receiving mephentermine

In phenylephirine group, $8(26 \%)$ developed bradycadia. Pulse rate dropped to 50 beats per minute and only $3(10 \%)$ patients developed severe bradycardia pulse rate ranging 
between 42 to 45 beats per minute which was corrected by giving injection atropine so total $11 / 30$ ie $36 \%$ had bradycardia and $26 \%$ of patients developed headache. Shivering was seen in $28 \%$ patients (Figure 6). Its action being quick and short and mean arterial pressure which had dropped to 55 increased to 80 within 1 minute after intravenous bolus.

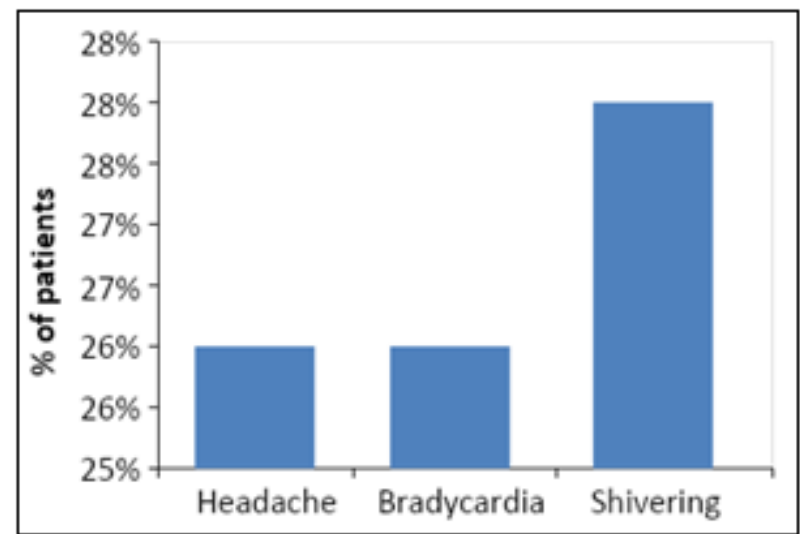

Figure 6: Side effects in patients receiving phenylephrine

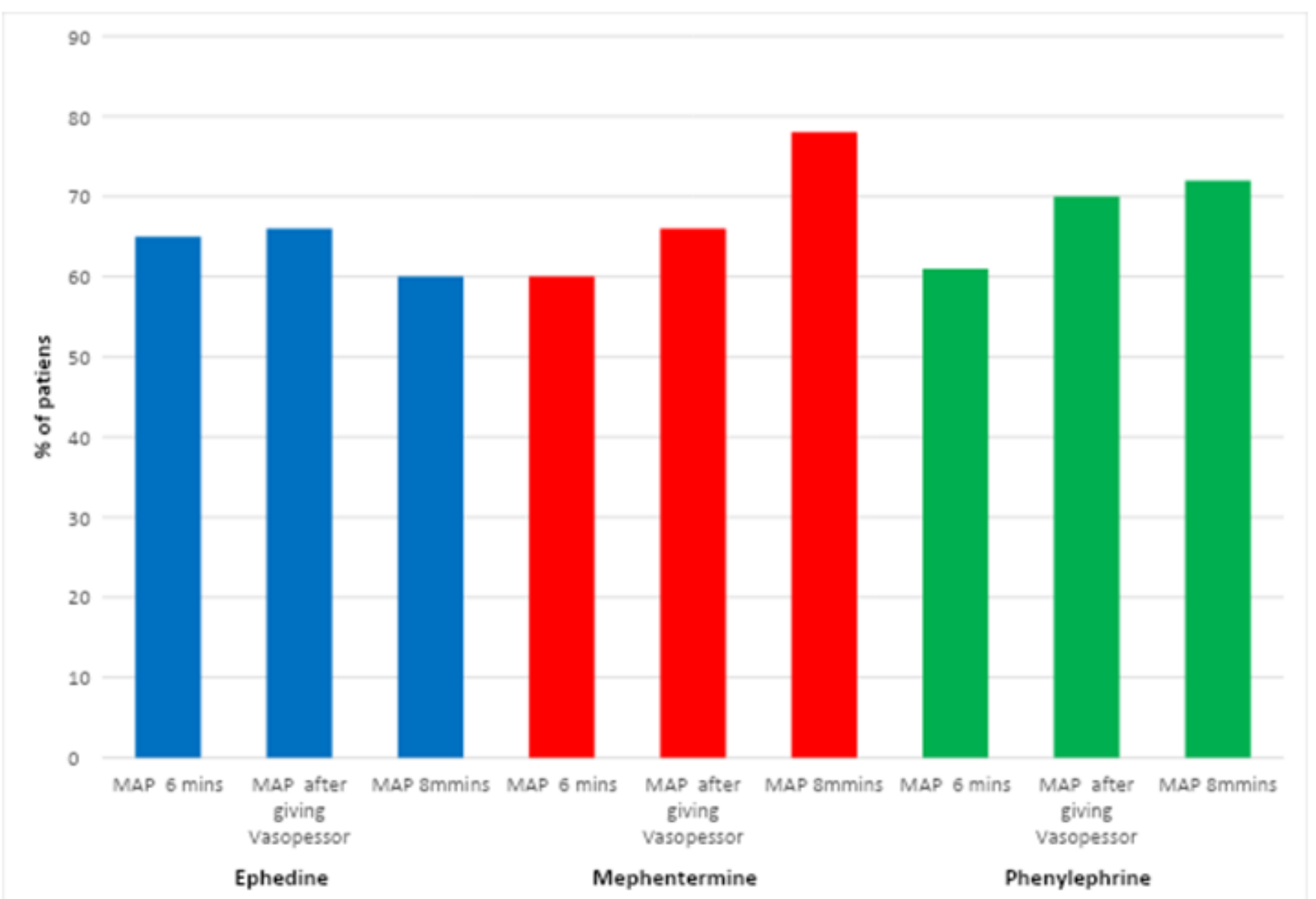

Figure 8: Comparison of three groups i.e. ephedrine, mephentermine and phenylephrine 


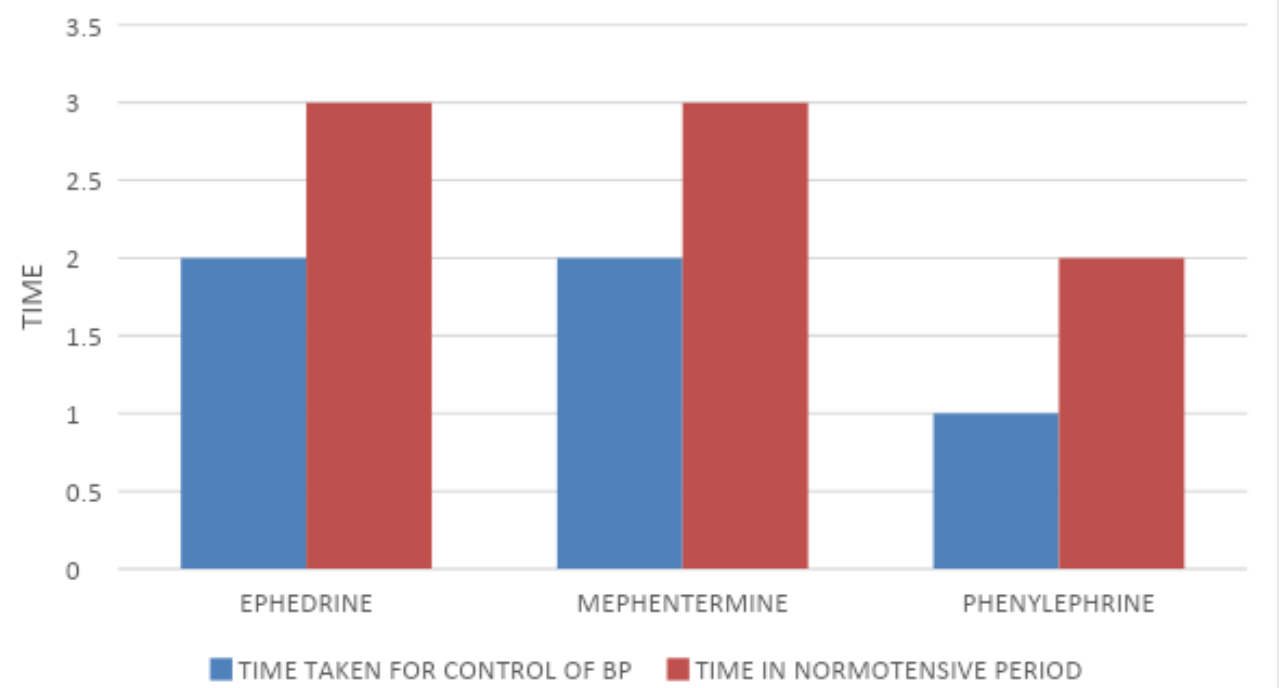

Figure 9: Onset and duration of response in three group

\section{Discussion}

Hypotensive effects of spinal anesthesia are widely studied in Ceasarean Sections which occur due to the compounding effects of aortocaval compression and various physiological changes of pregnancy. Despite being the subject of research since decades with numerous attempts to restrict the incidence it still remains an important cause for concern ${ }^{6}$. It has been realized that hypotension can be a major limiting factor for a more widespread use of spinal anaesthesia. Vasopressors with different pharmacoTogical actions are used for counteracting spinal hypotension. Intravenous bolus or infusion of vasopressors with side by side monitoring of patients response has a greater margin of safety and better flexibility. The aim of the present study was to compare the use of Phenylephrine, Ephedrine, and Mephentermine for control of Blood pressure for spinal induced hypotension in below umbilical surgeries The commonest procedure in each type of surgery performed was Total abdominal hysterectomy with salpingo- -oophorectomy or Vaginal hystectomies as $55 \%$ of patients in the study group were females from Gynaec operation theatre and $44 \%$ of patients were from Orthopedic operation theatre undergoing lower limb surgeries. In Group C as compared to Group A and Group B Bradycardia was an important finding and similar observation was also made by Bhattarai et al. ${ }^{7}$ Tachycardia was noted in patients who received Ephedrine or Mephentrimine while bradycardia was noted with Phenylephirine which was corrected with injection Atropine
$0.6 \mathrm{mg}$ as reported by Mohta et $a l^{8}$ was also seen in the present study . All the three vasopessor agents were equally effective in maintaining the vital parameters like heart rate and blood pressure as was also found in the study done by Mahajan et al., ${ }^{9}$. Nausea and Vomiting occurred in all the groups but was more associated with hypotension ${ }^{10}$ Mean arterial pressure was found to be higher in group $\mathrm{C}$ as compared to the other two groups as was seen in a study done by Sahu et al. ${ }^{11}$. Action of Ephedrine and mephentermine is on both alpha and beta receptors, whereas phenylephrine has pure alpha receptors' activity. ${ }^{12,13,14} \mathrm{~A}$ study done by Ganeshnavar et al. ${ }^{15}$ had findings which were in consonance with the present study. Similar results have been obtained in the present study as the in studies mentioned above except hypertension in $13 \%$ of patients in who received Mephentramine because of its ionotropic action and headache in $26 \%$ of cases in phenylephrine group . The results of the present study are directly related to the the pharmacological actions of the vasopressor agents Mephenteramine with positive inotropic and chronotropic effect increases the force of contraction of heart. It also produces a positive effect at the sinoatrial node but this effect is usually overcome by increased vagal activity occurring as a reflex to increased blood pressure. Phenylephrine, on the other hand, is a direct-acting synthetic noncatecholamine that principally stimulates the alpha1adrenergic receptors with minimal effect on the betaadrenergic receptors

\section{Comparison of our study with similar studies by various authors}

\begin{tabular}{|c|c|c|c|}
\hline Authors & Group A & Group B & Group $C$ \\
\hline Shifaat et al. ${ }^{1}$ & $\begin{array}{l}\text { Equally effective in correcting } \\
\text { hypotension }\end{array}$ & $\begin{array}{l}\text { Equally effective in correcting } \\
\text { hypotension }\end{array}$ & $\begin{array}{c}\text { Equally effective in } \\
\text { correcting hypotension }\end{array}$ \\
\hline $\begin{array}{l}\text { Kamalakannan and } \\
\text { Anandha Lakshmi. }\end{array}$ & $\begin{array}{c}\text { maintenance of maternal arterial pressure } \\
\text { within } 20 \% \text { limit of baseline values, }\end{array}$ & $\begin{array}{c}\text { maintenance of maternal arterial pressure } \\
\text { within } 20 \% \text { limit of baseline values, }\end{array}$ & $\begin{array}{l}\text { Quicker peak in BP and } \\
\text { bradycardia }\end{array}$ \\
\hline Kaur D, et al ${ }^{6}$ & Tachycardia & \begin{tabular}{|c|} 
Tachycardia \\
\end{tabular} & Bradycardia \\
\hline Bhattarai et al $^{7}$ & Tachycardia & Tachycardia & Bradycardia \\
\hline Mohta et al ${ }^{8}$ & Tachycardia & Tachycardia & Bradycardia $(23 \%)$ \\
\hline Mahajan et al $^{9}$ & Tachycardia & Tachycardia & Bradycardia \\
\hline Present Study & Tachycardia & Tachycardia & Bradycardia $(26 \%)$ \\
\hline
\end{tabular}




\section{Limitations of the Study}

Small number of patients and single centre study are the limitations of our work Larger studies are required to confirm our observations.

\section{Conclusion}

Effectiveness of ephedirine, mephentramine and phenylephirine was almost equal in controlling the blood pressure for spinal induced hypotension for below umbilical surgeries without any detrimental effects on outcome. Elevation of systolic arterial pressure in phenyephrine was significantly high for first 6 minutes of bolus dose as compared to other two drugs. Significant bradycardia was noted in phenylephrine group.

\section{References}

[1] Shifaar F, Syed SI, Gupta S, Danish Q, Wani HA. Comparison of ephedrine, mephentermine and phenylephrine for maintenance of blood pressure during spinal anaesthesia. Int $\mathbf{J}$ Med Res Prof 2016;2:51-58

[2] David LB. Spinal, epidural and caudal anaesthesia; Eds; Millers Anaesthesia: Elsevier Churchill Livingstone; Sixth editions; 2004: 43: 1653-168

[3] Kundra P, Veena P. General endotracheal anaesthesia for lower segment caesarean section: a vanishing art? OA Anaesthetics 2013; 1:7.

[4] Kamalakannan M, Lakshmi A. Comparative effect of ephedrine, mephentermine and phenylephrine during spinal anesthesia. Annals of International Medical and Dental Research 2017;3:58--64

[5] Johnston I. Vasopressors for sub-arachnoid anaesthesia in obstetrics. Update Anaesth. 2005; 20: 2-6.

[6] Kaur D, Khan AL, Pathak A. A comparative study of three vasopressors for maintenance of blood pressure during spinal anesthesia in lower abdominal surgeries Anesthesia: Essays and Researches 2018;12:353-358

[7] Bhattarai B, Bhat SY, Upadya M. Comparison of bolus phenylephrine, ephedrine and mephentermine for maintenance of arterial pressure during spinal anesthesia in cesarean section. JNMA J Nepal Med Assoc. 2010; 49:23-8.

[8] Mohta M, Aggarwal M, Sethi AK, Harisinghani P, Guleria K. Randomized double-blind comparison of ephedrine and phenylephrine for management of post-spinal hypotension in potential fetal compromise. Int J Obstet Anesth. 2016; 27:32-40.

[9] Mahajan L, Anand LK, Gomber KK. A randomized double-blinded comparison of ephedrine, phenylephrine and mephentermine infusions to maintain blood pressure during spinal anaesthesia for cesarean delivery: The effects on fetal acid-base status and haemodynamic control. J Anaesth Clin Pharmacol. 2009; 25: 427-32.

[10] Adigun TA, Amanor-Boadu SD, Soyannwo OA. Comparison of intravenous ephedrine with phenylephrine for the maintenance of arterial blood pressure during elective caesarean section under spinal anaesthesia. Afr J Med Med Sci. 2010;39:1320.

[11] Sahu D, Kothari D, Mehrotra A. Comparison of bolus phenylephrine, ephedrine and mephentermine for maintenance of arterial pressure during spinal anaesthesia in caesarean section - A clinical study. Indian J Anaesth. 2003; 47:125-8.

[12] Mohta M, Janani SS, Sethi AK, Agarwal D, Tyagi A. Comparison of phenylephrine hydrochloride and mephentermine sulphate for prevention of post spinal hypotension. Anaesthesia. 2010; 65:1200-5.

[13] Ramesh R, Dayananda VP, Bhaskara P. Evaluation of pre-emptive inrtramuscular phenylnephrine at different dose for reduction of hypotension under spinal anaesthesia. Int $\mathbf{J}$ Recent Trends Sci Tech. 2014; 12:137-40.

[14] Kansal A, Mohta M, Sethi AK, Tyagi A, Kumar P. Randomised trial of intravenous infusion of ephedrine or mephentermine for management of hypotension during spinal anaesthesia for caesarean section. Anaesthesia. 2005; 60:28-34.

[15] Ganeshnavar A, Uday SA, Adarsh ES, Prakashappa DS, Ramesh K, Ravi R. Comparison of bolus phenylephrine, ephedrine and mephentermine for maintenance of arterial pressure during spinal anaesthesia in caesarean section. J Clin Diagn Res. 2011;5:94 